Research Article

\title{
Flexural Behavior of Corroded Reinforced Recycled Aggregate Concrete Beams
}

\author{
Taoping Ye $\mathbb{D},{ }^{1}$ Wanlin Cao $\mathbb{D},{ }^{1}$ Yixuan Zhang, ${ }^{2}$ and Zhengwen Yang ${ }^{3}$ \\ ${ }^{1}$ College of Architecture and Civil Engineering, Beijing University of Technology, Beijing 100124, China \\ ${ }^{2}$ State Grid Beijing Electric Power Company, Beijing 100031, China \\ ${ }^{3}$ Beijing Zhonglu Yuantong Engineering Consulting Co., Ltd., Beijing 100085, China
}

Correspondence should be addressed to Wanlin Cao; wlcao@bjut.edu.cn

Received 11 August 2017; Revised 21 December 2017; Accepted 14 January 2018; Published 1 April 2018

Academic Editor: Marco Rossi

Copyright ( $\odot 2018$ Taoping Ye et al. This is an open access article distributed under the Creative Commons Attribution License, which permits unrestricted use, distribution, and reproduction in any medium, provided the original work is properly cited.

Recycling concrete not only reduces the use of virgin aggregate but also decreases the pressure on landfills. As a result, recycled coarse aggregate (RCA) is extensively recommended for new construction projects. However, the flexural behavior of corroded reinforced recycled aggregate concrete (RAC) beams is uncertain. The experimental research presented in this paper was performed to investigate the flexural behavior of corroded reinforced RAC beams compared to that of corroded reinforced natural aggregate concrete (NAC) beams and consequently explore the possibility of using RAC beams in corrosive environments. Four different percentages of RCA in total mass of coarse aggregate in concrete mixtures $(0 \%, 33 \%, 66 \%$, and $100 \%)$ and two different concrete strengths (C30, C60) were the governing parameters. The electrochemical method was adopted to accelerate steel corrosion. Full-scale tests were performed on eight simply supported beams until the failure load was reached. Comparison of load-deflection behavior, crack patterns, failure modes, ductility, and ultimate flexural capacity of corroded reinforced NAC and RAC beams was made based on the experimental results obtained. The comparison results show that the flexural behavior of corroded reinforced RAC beams with an appropriate percentage of RCA is satisfactory compared to the behavior of NAC beams.

\section{Introduction}

The amount of concrete waste has increased significantly over the years owing to reconstruction and the demolition of old buildings and has become a serious global environmental concern. Recycling of waste concrete is one of the sustainable solutions for the growing waste disposal crisis and depletion of natural aggregate sources. As a result, recycled coarse aggregate (RCA) is being produced for various applications, and a number of studies have been carried out to examine its fundamental properties and mixture design. Researchers [1-7] have found that RCA has inherent randomness and variability owing to differences in concrete raw materials and technical factors. Some researchers $[8,9]$ have shown that the strength of recycled aggregate concrete (RAC) is similar to that of natural aggregate concrete (NAC). However, Sami et al. [10] found that the strength of RAC is lower than that of NAC. Elasticity modulus of RAC decreases with the addition of recycled aggregate [11, 12]. Xiao and Falkner [13] found that under the equivalent mix proportion, the bond strength between RAC and plain rebar decreases with an increase of RCA replacement percentage, whereas the bond strength between RAC and deformed rebar has no obvious relation with RCA replacement percentage.

Various studies have also examined the mechanical properties, mixture design, and structural performance of reinforced concrete beams comprising recycled aggregate. Numerous researchers have investigated the flexural behavior of reinforced RAC beams, with their results showing that the flexural performance of beams made of RAC is comparable to that of beams made of conventional NAC [14-18]. However some researchers [19] have found that the maximum flexural strength of RAC decreases for specimens at $100 \%$ replacement, regardless of the water-cement ratio. Further investigation [20] has shown that the use of fine 
RCA in structural elements does not significantly affect their flexural performance, and these materials increase the elements' ductility, leading to greater dissipation capacity of energy at the plastic phase. Tests also show that the shear capacity of a RAC beam is comparable to that of a companion beam made of conventional concrete [21, 22]. Some beam results do not follow the expected trends, and those may be related to the RAC properties.

However, it should be noted that the above studies on reinforced RAC beams were conducted in ideal environments without corrosive mediums. In fact, a corrosive environment such as seawater is very harmful to the applicability and security of structure or component. Tests have shown that different corrosion ratios of longitudinal bars have a different impact on the flexural properties of corroded reinforced concrete beams with $100 \%$ replacement of coarse aggregate [23]. Tests have also shown that increasing the rebar corrosion level gradually weakens the antisliding ability of reinforced RAC, and the ultimate bond strength of reinforced RAC slightly decreases with an increase of RCA replacement. However, the relative bond strength between uncorroded rebar and RAC is minimally affected by the RCA content [24]. In addition, the antipermeability property of RAC decreases with increase in the recycled aggregate replacement percentage $[25,26]$. From the standpoint of promoting resource and energy savings, environmental preservation, and the structural application of recycled aggregates, it is essential to study whether concrete made of recycled aggregates - that is, RAC-can be effectively used as a structural beam under corrosive circumstances. This paper provides additional experimental data on the flexural behavior of corroded reinforced RAC beams with the objective of using RAC in structural concrete elements (beams) under corrosive circumstances.

The methodology used in this study was to compare the flexural performance of corroded reinforced concrete beams made of NAC and to that of RAC. As the antipermeability property of RAC is related to RCA replacement percentage and the performance of medium-strength concrete and high-strength concrete are different, four different percentages of RCA in total mass of coarse aggregate in concrete mixtures $(0 \%, 33 \%, 66 \%$, and $100 \%)$ and two different concrete strengths (C30, C60) were the governing parameters in this analysis. All specimens were designed to have the same structure, size, reinforcement ratio, and corrosion ratio. The electrochemical method was adopted to accelerate steel corrosion. Full-scale tests up to failure load on eight simply supported beams were conducted to investigate the flexural behavior of corroded reinforced RAC beams. The experimental results were then analyzed to obtain more general conclusions concerning the flexural behavior of RAC beams compared to that of NAC beams under corrosive circumstances.

\section{Materials and Methods}

2.1. Component Materials. Common Portland cement type 42.5, conforming to the Chinese standard GB 175-2007, machine-made sand with a fineness modulus of 2.6, tap

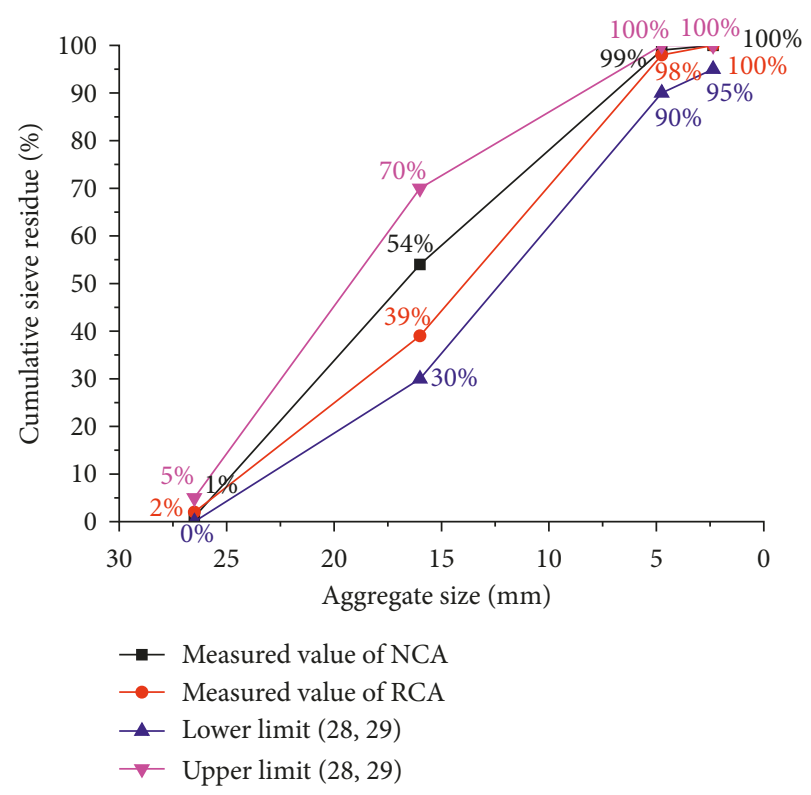

FIgURE 1: The grading curves of the NCA and RCA.

water, Grade I Class F coal fly ash, and granulated blast furnace slag with strength grade S95 were used in this research. The natural coarse aggregate (NCA) was gravel with continuous grain size having diameters between $5 \mathrm{~mm}$ and $25 \mathrm{~mm}$, conforming to the Chinese standard GB/T 14685-2011 [27]. The RCA was obtained by processing waste concrete from demolished concrete structures in Beijing, where the properties of the original concrete were unknown. The RCA conforms to the Chinese standard GB/T 25177-2010 [28]. Figure 1 shows the grading curves of the NCA and RCA. Table 1 lists the fundamental physical properties of RCA and NCA. Deformed (i.e., crescent ribbed) low-carbon steel rebars of HRB400 were used in the longitudinal bars and erection bars, with diameter sizes $14 \mathrm{~mm}$ and $12 \mathrm{~mm}$, respectively; plain bars of HPB300 with a diameter size of $6 \mathrm{~mm}$ was adopted for the stirrup. The mechanical properties of the steel bars are shown in Table 2 .

2.2. Concrete Mixtures and Properties. Because of its high water absorption rate, the used RCAs were presoaked in additional water before mixing. The water amount used to presoak the RCAs was calculated on the basis of the saturated surface-dry condition. The main differences between the eight groups were the RCA replacement percentage $(0 \%$, $33 \%, 66 \%$, and $100 \%$ ) and concrete strengths (C30 and C60). The ratio of the recycled to the total aggregates (by weight) is termed the RCA replacement percentage $(r)$. As the densities of RCA and NCA are substantially different, the volumetric composition of the different mixes also differs. Therefore, replacing the RCA by mass is not the best method. The mixtures were divided into eight groups, and the experiments were carried out under the same laboratory conditions. Normal concrete (NC), that is, concrete with $r=0$, served as reference concrete. According to RCA replacement 
TABLE 1: Physical properties of RCA and NCA.

\begin{tabular}{lcccccc}
\hline $\begin{array}{l}\text { Coarse } \\
\text { aggregate }\end{array}$ & $\begin{array}{c}\text { Bulk density } \\
\left(\mathrm{kg} / \mathrm{m}^{3}\right)\end{array}$ & $\begin{array}{c}\text { Apparent density } \\
\left(\mathrm{kg} / \mathrm{m}^{3}\right)\end{array}$ & $\begin{array}{c}\text { Water absorption } \\
(\%)\end{array}$ & $\begin{array}{c}\text { Crushing index } \\
(\%)\end{array}$ & $\begin{array}{c}\text { Needle-like particle } \\
\text { content }(\%)\end{array}$ & $\begin{array}{c}\text { Mud content } \\
(\%)\end{array}$ \\
\hline Natural & 1464.27 & 2760.24 & 0.42 & 9.71 & 4.98 & 0.41 \\
Recycled & 1252.98 & 2575.05 & 2.99 & 13.10 & 3.01 & 2.25 \\
\hline
\end{tabular}

TABLE 2: Mechanical properties of the steel bars.

\begin{tabular}{|c|c|c|c|c|c|}
\hline Type & Nominal diameter $(\mathrm{mm})$ & Yield strength $\left(\mathrm{N} / \mathrm{mm}^{2}\right)$ & Ultimate strength $\left(\mathrm{N} / \mathrm{mm}^{2}\right)$ & Elastic modulus $\left(\mathrm{N} / \mathrm{mm}^{2}\right)$ & Elongation (\%) \\
\hline HPB300 & 6 & 470.7 & 670.0 & $1.98 \times 10^{5}$ & 13.7 \\
\hline HRB400 & 12 & 487.3 & 627.3 & $1.99 \times 10^{5}$ & 18.6 \\
\hline HRB400 & 14 & 496.7 & 645.0 & $2.03 \times 10^{5}$ & 20.8 \\
\hline
\end{tabular}

TABLE 3: Mix proportions of concrete.

\begin{tabular}{|c|c|c|c|c|c|c|c|c|c|c|}
\hline \multirow{2}{*}{ Specimen } & \multirow{2}{*}{ Water/binder ratio } & \multicolumn{7}{|c|}{ Unit weight $\left(\mathrm{kg} / \mathrm{m}^{3}\right)$} & \multirow{2}{*}{$f_{\mathrm{cu}}(\mathrm{MPa})$} & \multirow{2}{*}{$E_{\mathrm{c}}\left(\mathrm{N} / \mathrm{mm}^{2}\right)$} \\
\hline & & Cement & Coal fly ash & Slag & Sand & Gravel & RCA & Water & & \\
\hline RCB-0 & 0.52 & 227 & 75 & 75 & 910 & 910 & 0 & 195 & 36.1 & $3.18 \times 10^{4}$ \\
\hline RCB-33 & 0.52 & 227 & 75 & 75 & 910 & 610 & 300 & 195 & 36.4 & $3.05 \times 10^{4}$ \\
\hline RCB-66 & 0.52 & 227 & 75 & 75 & 910 & 310 & 600 & 195 & 37.4 & $3.05 \times 10^{4}$ \\
\hline RCB-100 & 0.52 & 227 & 75 & 75 & 910 & 0 & 910 & 195 & 36.6 & $2.38 \times 10^{4}$ \\
\hline HRCB-0 & 0.39 & 435 & 52 & 52 & 758 & 928 & 0 & 210 & 63.9 & $3.72 \times 10^{4}$ \\
\hline HRCB-33 & 0.39 & 435 & 52 & 52 & 758 & 623 & 305 & 210 & 57.1 & $3.30 \times 10^{4}$ \\
\hline HRCB-66 & 0.39 & 435 & 52 & 52 & 758 & 315 & 613 & 210 & 57.9 & $3.02 \times 10^{4}$ \\
\hline HRCB-100 & 0.39 & 435 & 52 & 52 & 758 & 0 & 928 & 210 & 56.6 & $2.96 \times 10^{4}$ \\
\hline
\end{tabular}

$f_{\text {cu }}$ denotes the compressive strength of concrete cubes; $E_{\mathrm{c}}$ denotes the elasticity modulus of concrete.

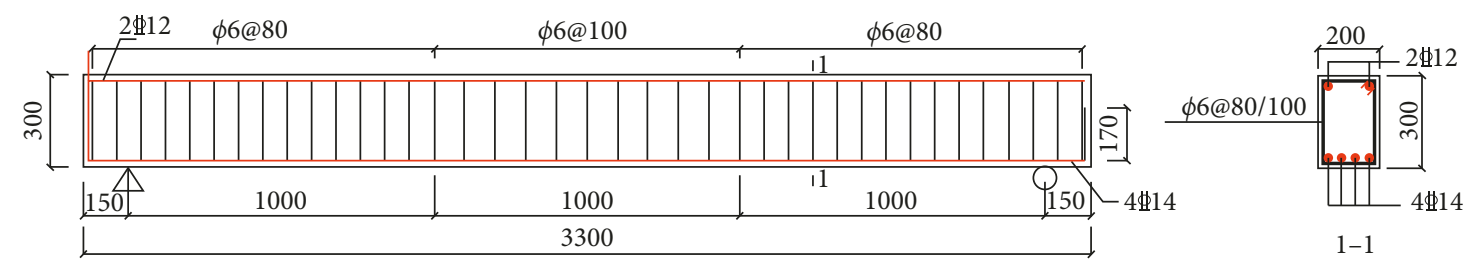

FIGURE 2: Specimen size and reinforcement details (unit: $\mathrm{mm}$ ).

percentage and concrete strengths, the specimen numbers were expressed as RCB-r or HRCB-r, in which recycled concrete (RC) specimens have a strength grade of C30 and high-strength recycled concrete (HRC) specimens have a strength grade of $\mathrm{C} 60$, with $\mathrm{B}$ representing the beam and $r$ signifying the RCA replacement percentage in digital form. The mix proportions of the concrete, the compressive strength of the cubic specimens $(150 \mathrm{~mm} \times 150 \mathrm{~mm} \times$ $150 \mathrm{~mm}$ ), and the elasticity modulus of concrete are given in Table 3. The elasticity modulus of concrete decreases with increased RCA replacement percentage and increases with increased concrete strength.

2.3. Description of Beam Specimens. Eight beams were tested in total. All the beams had a rectangular cross section of $200 \mathrm{~mm}$ width, $300 \mathrm{~mm}$ depth, and a total length of $3.3 \mathrm{~m}$. They had the same structure, size, reinforcement, and corrosion ratio but different RCA replacement percentages $(0 \%, 33 \%, 66 \%$, and $100 \%)$ and concrete strengths (C30 and $\mathrm{C} 60)$. All the beams were designed to fail in flexure, that is,

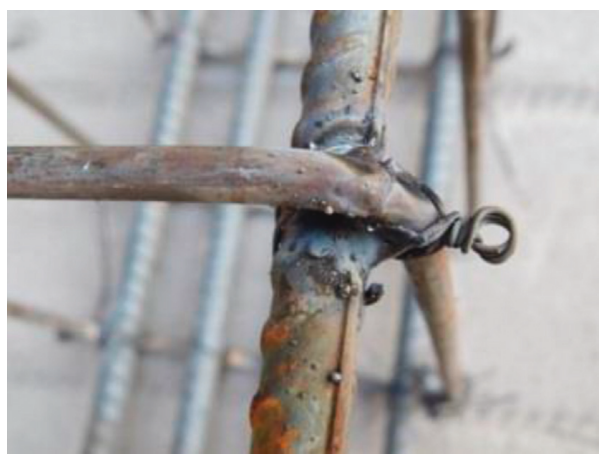

Figure 3: Processing of steel bar crossing points.

they were reinforced with sufficient transversal reinforcement to prevent shear failure. Figure 2 shows the specimen size and reinforcement details. The concrete protective layer was $25 \mathrm{~mm}$ thick, the ratio of longitudinal steel was $1.15 \%$, and the corrosion ratio of all the steel bars was $5 \%$. 


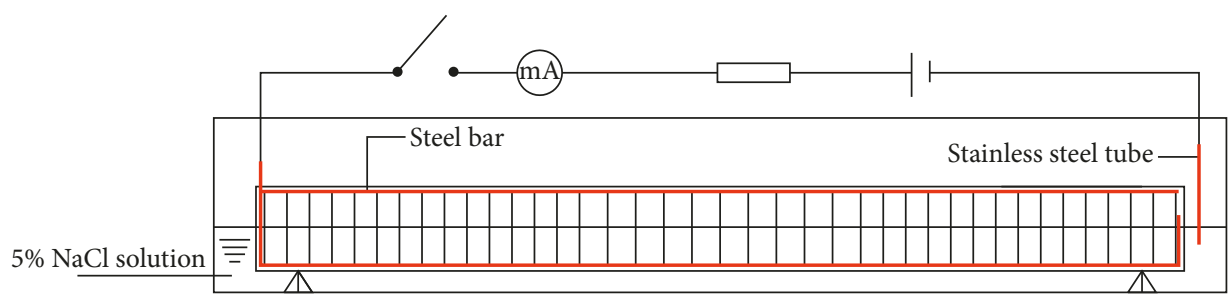

FIgURE 4: The accelerated corrosion device.

In practical engineering, corrosion of the stirrups occurs prior to that of the longitudinal bars in the beam. The diameter and area of the stirrup is smaller than that of the longitudinal bar, and the corrosion of the stirrup is heavier than that of the longitudinal reinforcement. This affects the performance of the beam to a certain extent. In order to simulate the corrosion status of steel in beams, all the longitudinal bars, stirrups, and erection bars were bound as a reinforcing cage and all the steel cross points were welded to ensure that all the steel bars were corroded after the application of electricity, as shown in Figure 3. The welded reinforcing cages were placed in the templates, and the specimens were cast in a horizontal position.

2.4. Electrochemical Corrosion Test. Under natural conditions, the corrosion of a steel bar in concrete is mainly caused by chemical reactions among the corrosive mediators, water, and oxygen, which is similar to the operating principle of a battery. As the progression of natural corrosion is very slow, using the natural corrosion method in tests is unrealistic. Therefore, in this study, the electrochemical method was adopted to obtain the corroded reinforced concrete beams in a short time. The advantage of this method is that the corrosion ratio can be calculated based on current intensity and corrosion time according to Faraday's first law of electrolysis.

To enable the $\mathrm{NaCl}$ solution to fully penetrate the steel surface and damage its passivation film, the beams were soaked in $5 \%$ concentration $\mathrm{NaCl}$ solution in a stainless steel pool for seven days, during which time the solution was tested regularly to maintain a steady liquid level and solution concentration. Subsequently, the solution height was adjusted to one-half that of the specimens (to ensure sufficient oxygen) and then plugged into DC regulated power. The anode connected to the rebar was exposed $50 \mathrm{~mm}$ above the beam; the cathode was connected to the stainless steel tube in the solution, as shown in Figure 4.

The corrosion current intensity was provided by DCregulated power, current density was $0.01-0.02 \mathrm{~mA} / \mathrm{mm}^{2}$ [29], and the final current intensity was $9.6 \mathrm{~A}$ according to the area of the corroded steel bars. The data were collected and adjusted every 12 hours to maintain constant current intensity. The corrosion time was determined when the mass corrosion ratio reached $5 \%$. During the accelerated corrosion process, the following actions had to be performed regularly: stirring of the $\mathrm{NaCl}$ solution to ensure even concentration in the electrolytic cell; testing of the $\mathrm{NaCl}$ solution to maintain stable solution height and concentration; and cleaning up corrosion substances in the cathode stainless steel tube to ensure an accelerating corrosion ratio.

2.5. Loading Schemes. All beams were simply supported with a span length of $3.0 \mathrm{~m}$ and subjected to four-point bending test in the test frame. The shear span to depth ratio was kept constant for all beam specimens. At one end, the specimen support was fixed hinge support, whereas at the other end, a sliding hinge support was utilized. Concrete strain gauges were installed to measure the concrete's strains, while beam deflections were measured by displacement meters. The layout of the test setup and measuring equipment is presented in Figure 5. The electrohydraulic servo loading system was utilized, and continual real-time data acquisition was achieved via an IMP (isolated measurement pod) data acquisition system. During the flexural test, the crack widths and crack patterns were observed and recorded until failure.

Before loading the specimens, preloading using $10 \mathrm{kN}$ weight was conducted to enable measuring instruments to function and stabilize the relationship between deformation and load. Monotonic multistage loading was first applied, followed by unidirectional repetitive loading when the yield load reached $80 \%$ of the estimated value. The testing was load-controlled in the elastic stage, the increment of load was about one-tenth of the calculated ultimate load, and displacement control was used in the elastoplastic stage. The specimens were considered to have reached or exceeded the limit of their bearing capacity if any of the following phenomena occurred: (1) breaking of tensile reinforcement; (2) concrete crushing in the compressive zone; (3) the maximum deflection value of the midspan reached onefiftieth of the calculation span (or $60 \mathrm{~mm}$ ); or (4) the maximum vertical crack width reached a value of $2.00 \mathrm{~mm}$.

2.6. Rust Inspection. The corrosion ratio of steel bars calculated using Faraday's law had a certain error compared to the actual corrosion ratio because of influence factors such as stray current in the process of accelerating corrosion with electricity, and the final corrosion ratio was determined by weighing. In order to calculate the mass loss after rebar corrosion, the rebar specimens were weighed using an electronic scale with precision $1 \mathrm{mg}$ and the measured gravity per length of the longitudinal bar was $1211 \mathrm{~g} / \mathrm{m}$.

To measure the precise mass corrosion ratio, all beams were broken apart and longitudinal bars near the specimen beams support were selected. Subsequently, in accordance with the method in Testing Code of Concrete for Port and 


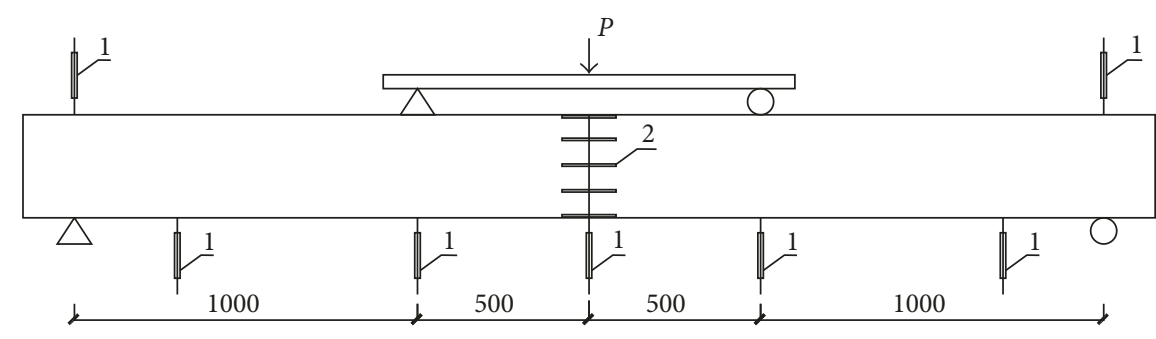

1. Displacement meter
2. Concrete strain gauge

(a)

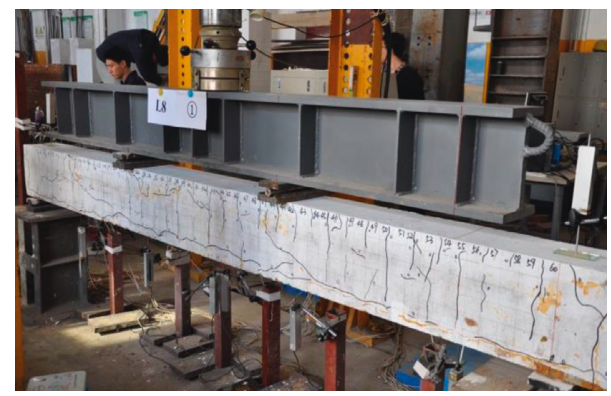

(b)

FIgURE 5: (a) Layout of test setup and measuring equipment (unit: mm). (b) Loading test arrangement.

Waterway Engineering (JTJ 270-98), the corrosion products on the surface of these rebars were cleaned using dilute hydrochloric acid and then neutralized with alkali. The specimens were then cleaned with water, weighed, and their length was measured. The ratio of the weight of the lost rebars to the initial weight is the actual corrosion ratio (precision of $0.01 \%$ ), which is calculated using (1). Owing to the complexity of the corrosion process, the corrosion ratios of all the longitudinal bars were varied; the average corrosion ratio was adopted to analyze the beams. Further, corroded longitudinal bars were selected and mechanical property tests were conducted.

$$
L_{\mathrm{m}}=\frac{m_{0}-m}{m_{0}} \times 100 \%,
$$

where $L_{\mathrm{m}}$ denotes the rebar corrosion ratio (\%), $m_{0}$ denotes the initial rebar mass $(\mathrm{g})$, and $m$ denotes the mass after corrosion (g).

\section{Results and Discussion}

3.1. Result of Accelerated Corrosion Test. At the beginning of electricity application, a large number of small bubbles escaped from the stainless steel tube. Subsequently, a layer of bronzing bubbles existed on the solution surface. The solution gradually became dark green and later reddish brown with increased electricity application time. Several tiny cracks and rust also appeared on the corrosive rebar. By the end of the electricity application period, brown nodules very visible at the ends and bottom of the beam, with more blackbrown nodules formed on those sites with relatively more corrosion. Corrosive cracks kept widening and expanding, and there was visible cracking, mainly caused by the corroded expansion at the bottom of the longitudinal rebar. Some concrete also fell off in some parts. The corrosion process is shown in Figure 6.

After accelerated corrosion, the specimens were cleaned and dried, the width of the corrosive cracks measured, and their positions recorded. The corrosive cracks are plotted in Figure 7.

3.2. Analysis of the Static Load Test. At the initial stage, very little visible effect occurred on the concrete surface, the loaddeflection curve was linear, and the concrete's strain and deflection were both very small. After the initial vertical crack was observed, flexural cracking propagated to the midspan close to the loading points. Subsequently, new flexural cracks appeared on the pure bending area and near the corrosion cracks, and their width was extending a certain distance along the beam height. After the midspan deflection suddenly increased with concrete cracking, the main stress crack kept widening - the load and midspan deflection curve are close to the horizontal line, that is, the reinforcement yielded and deformation increased rapidly, followed by the maximum vertical crack width reaching $2.00 \mathrm{~mm}$. Overall results indicate that the crack propagation, and failure mode of corroded reinforced RAC beams are similar, regardless of the replacement percentage with RCA and concrete strengths. Similar failure behavior was observed for all the specimens in this research. They underwent four stress process steps: elastic stage with corrosive cracks and without stress cracks, elastic-plastic stage with both corrosive cracks and stress cracks, yield stage of longitudinal bar, and failure stage after yield of reinforcement. 


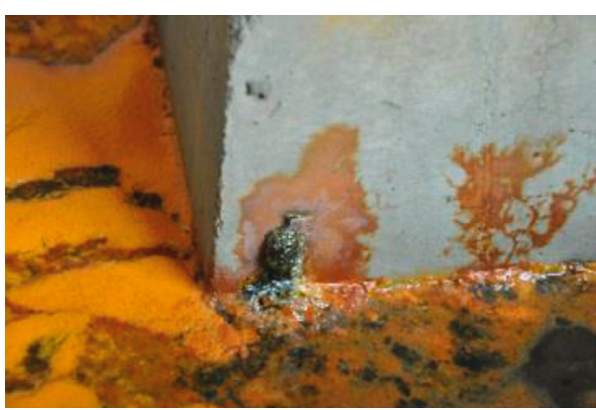

(a)

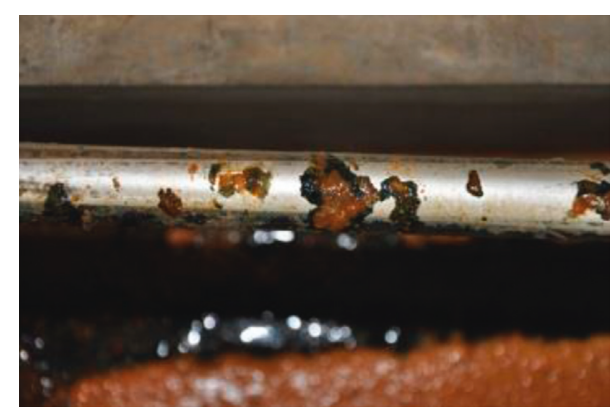

(b)

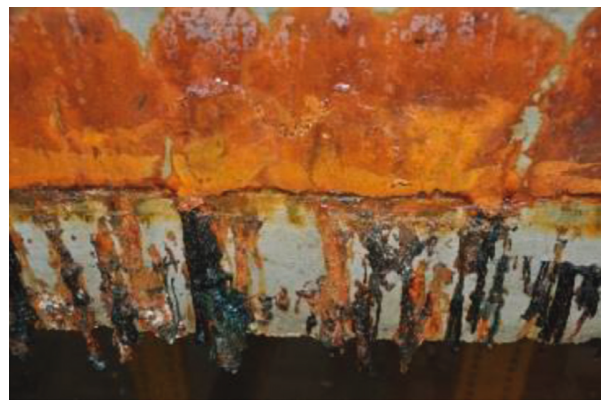

(c)

Figure 6: (a) Rust on the specimen. (b) Rust on the stainless steel tube. (c) The specimen after accelerated corrosion.

The summarized beam testing results are shown in Table 4. The ultimate load $\left(F_{\mathrm{u}}\right)$, the yielding load $\left(F_{\mathrm{y}}\right)$, and corresponding deflections $\left(d_{\mathrm{u}}, d_{\mathrm{y}}\right)$, as well as the cracking load $\left(F_{\mathrm{cr}}\right)$ and the displacement ductility ratio $(D)$, defined as the ratio of midspan displacement at the ultimate load $\left(d_{\mathrm{u}}\right)$ to the midspan displacement at the yield of reinforcement $\left(d_{\mathrm{y}}\right)$, are given.

When the concrete is middle strength, the cracking load of RCB-33 and RCB-66 are comparable with RCB-0, whereas the cracking load of RCB-100 decreases. When the concrete is high strength, the cracking load for HRCB-33 and HRCB-0 is virtually the same, and HRCB-66 and HRCB-100 decrease but are relatively close. The ultimate loads of RCB-33 and RCB-66 are comparable with RCB-0, whereas the ultimate load of RCB-100 is $4.99 \%$ lower than that of RCB-0. The decrease in the ultimate load of middle-strength RAC declines by $1.18 \%$ on average compared with RCB- 0 . The ultimate loads of HRCB-33, HRCB-66, and HRCB-100 are $1.67 \%, 2.91 \%$, and $6.62 \%$ lower than that of HRCB-0, respectively. The decrease in the ultimate load of high-strength RAC declines by $3.74 \%$ on average compared with HRCB- 0 . This shows that RCA replacement percentage and concrete strength grade have little effect on ultimate load.

When the specimens failed, the midspan ultimate deflection of RCB-33 and RCB-66 was close to that of RCB-0, and the deflection of RCB-100 abruptly decreased. The deflection between HRCB-33 and HRCB-0 was consistent. However, the deflection of HRCB-66 and HRCB-100 decreased with increased RCA replacement percentage.

The displacement ductility ratio $D$ of middle and high strengths ranges from 3.43 to 2.10 , and from 3.62 to 1.98 , respectively. The value of $D$ for RCB-33 and RCB-66 is $2.92 \%$ and $12.24 \%$ higher than that of RCB-0, respectively, but RCB-100 is $38.78 \%$ lower than that of RCB-0. The value of $D$ declines by $7.87 \%$ on average compared with RCB- 0 . The value of $D$ for HRCB-33 is $0.83 \%$ higher than that of HRCB-0, but HRCB-66 and HRCB-100 are $28.18 \%$ and $45.30 \%$ lower than that of RCB- 0 , respectively. The value of $D$ declines by $24.22 \%$ on average compared with HRCB-0. The results indicate that the displacement ductility ratio of the beams is significantly affected by RCA replacement percentage, which shows different characteristics with concrete strength grades. The effects are greater for the high-strength concrete than the middle-strength concrete. It can be explained by the fact that the brittleness of RC increases with increased RCA replacement percentage and concrete strength grade.

After electric corrosion, the specimens became more likely to transform from appropriate reinforcement beam failure to rare-reinforced beam failure, as all specimen failures were only embodied in the yield of reinforcement without crushing of compressive concrete. All specimens were believed to be failed as soon as the maximum vertical crack width reached $2.00 \mathrm{~mm}$. The crack patterns of beams at failure are shown in Figure 8.

From the figure, it can be seen that when the concrete was middle strength, and many stress cracks with small spacing appeared on the pure bending section of the specimens. In contrast, when the concrete was high strength, fewer stress cracks with large spacing appeared on the pure bending section, and a few cracks also occurred on the bending shear section. This signifies that the higher the concrete strength is, the greater the brittleness. Thus, the concrete ductility was suppressed, and the quantity of 


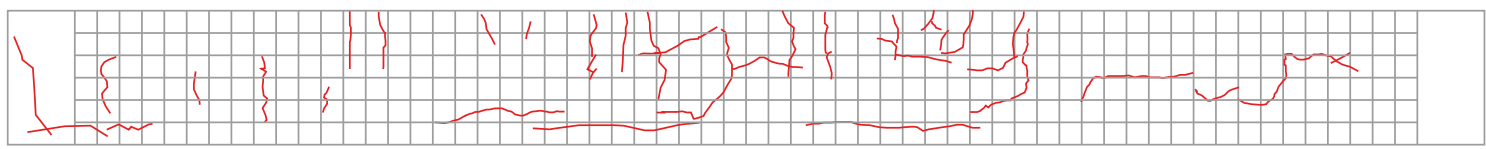

(a)

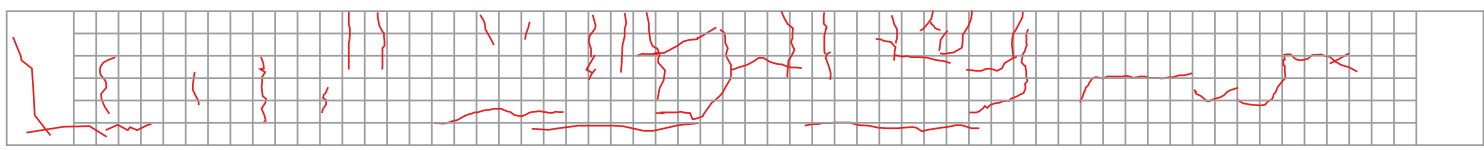

(b)

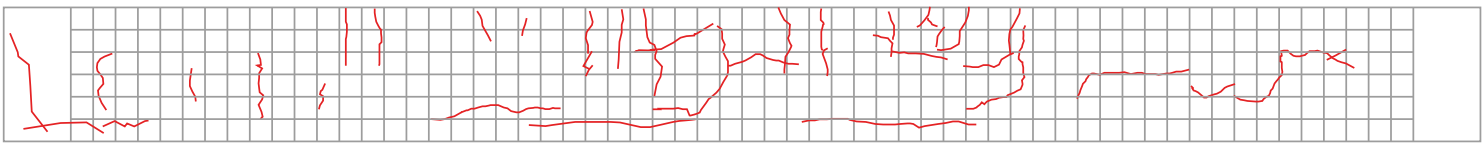

(c)

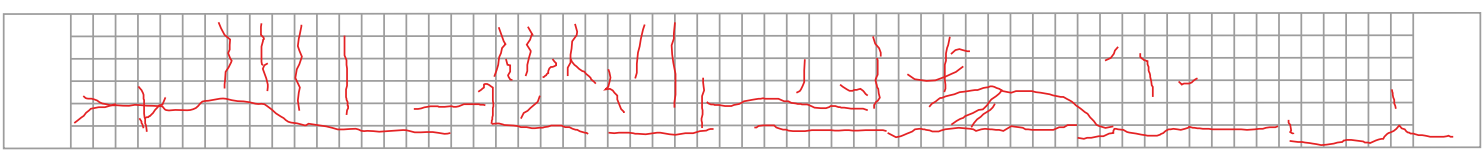

(d)

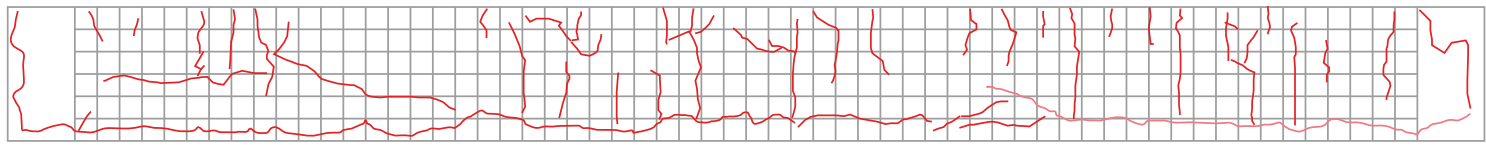

(e)

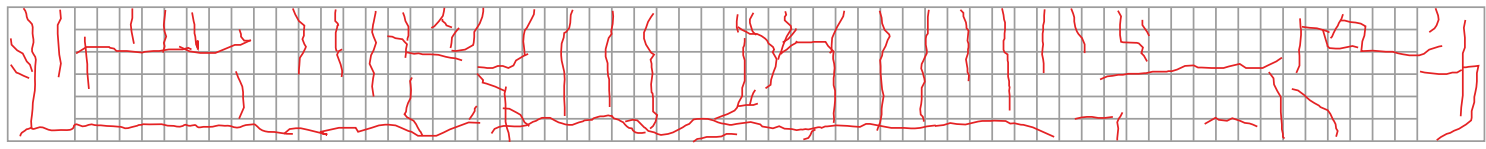

(f)

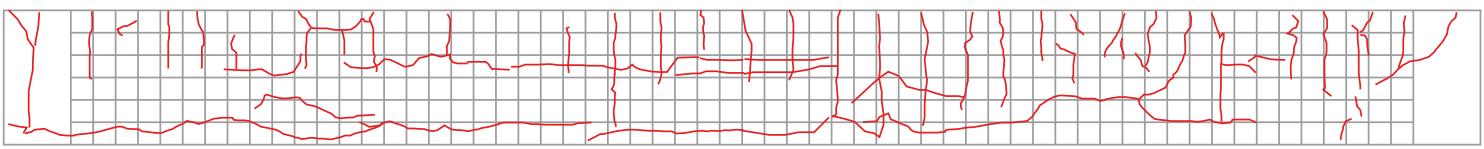

(g)

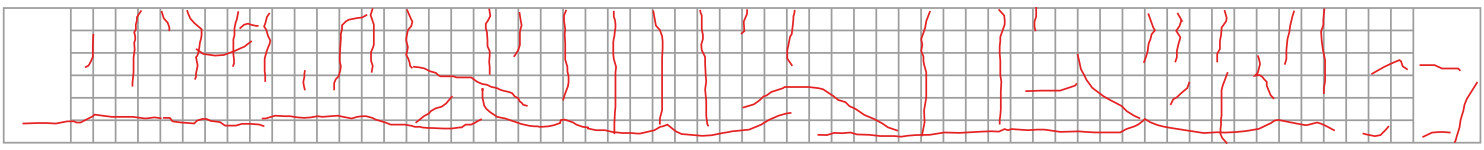

(h)

FiguRE 7: Corrosive cracks on the eight specimens after electricity application. (a) RCB-0, (b) RCB-33, (c) RCB-66, (d) RCB-100, (e) HRCB-0, (f) HRCB-33, (g) HRCB-66, and (h) HRCB-100.

TABLE 4: Results of the loading test.

\begin{tabular}{lcccrr}
\hline Specimen & $F_{\mathrm{cr}}(\mathrm{kN})$ & $F_{\mathrm{y}}(\mathrm{kN})$ & $F_{\mathrm{u}}(\mathrm{kN})$ & $d_{\mathrm{y}}(\mathrm{mm})$ & $d_{\mathrm{u}}(\mathrm{mm})$ \\
\hline RCB-0 & 29.7 & 132.2 & 138.2 & 14.94 & 51.24 \\
RCB-33 & 30.2 & 125.6 & 140.2 & 14.04 & 49.55 \\
RCB-66 & 30.3 & 126.3 & 138.2 & 13.29 & 51.13 \\
RCB-100 & 20.5 & 131.4 & 131.3 & 14.32 & 3.43 \\
HRCB-0 & 30.2 & 123.9 & 137.4 & 13.89 & 3.03 \\
HRCB-33 & 30.3 & 123.6 & 135.1 & 13.95 & 50.23 \\
HRCB-66 & 20.7 & 126.6 & 133.4 & 15.50 & 50.91 \\
HRCB-100 & 21.0 & 123.9 & 128.3 & 15.26 & 40.19 \\
\hline
\end{tabular}




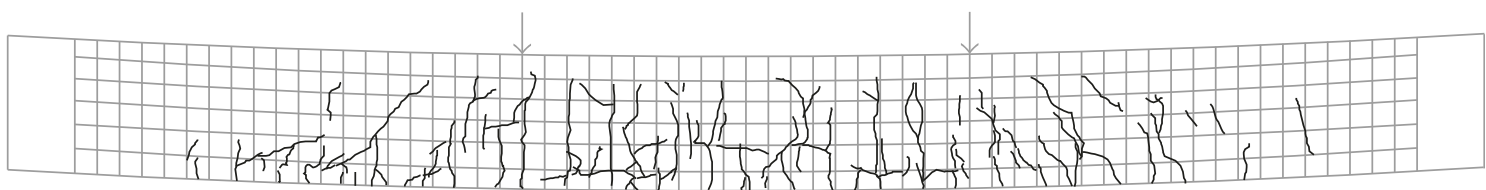

(a)

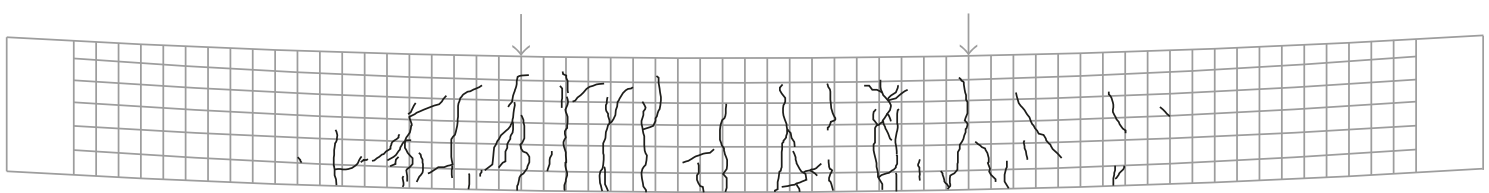

(b)

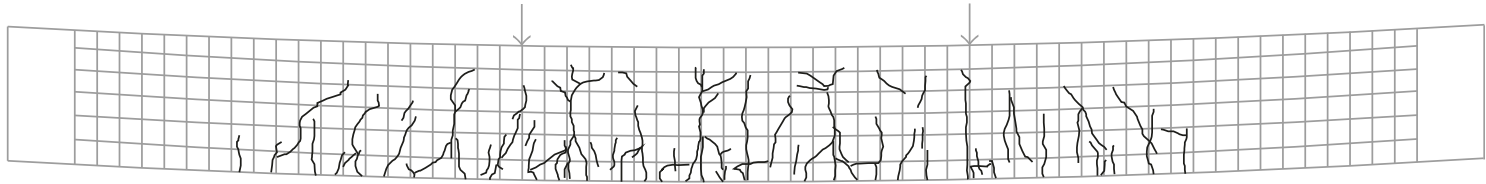

(c)

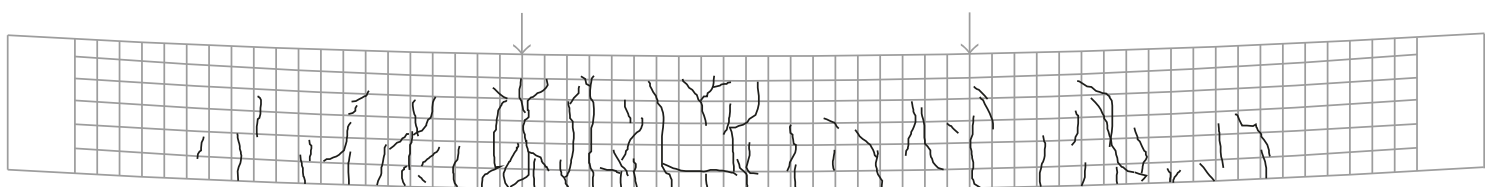

(d)

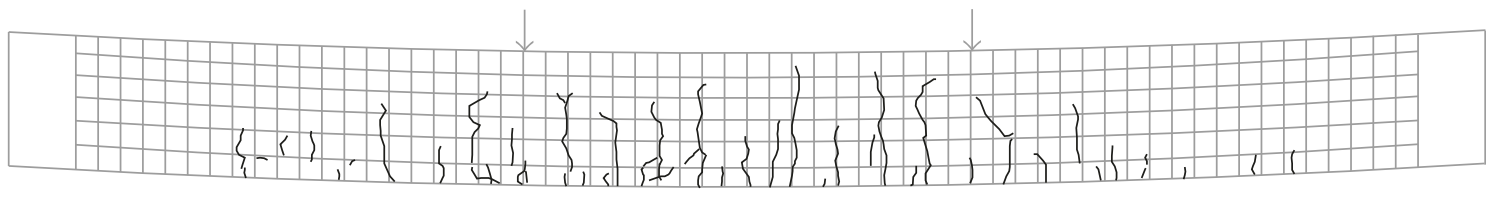

(e)

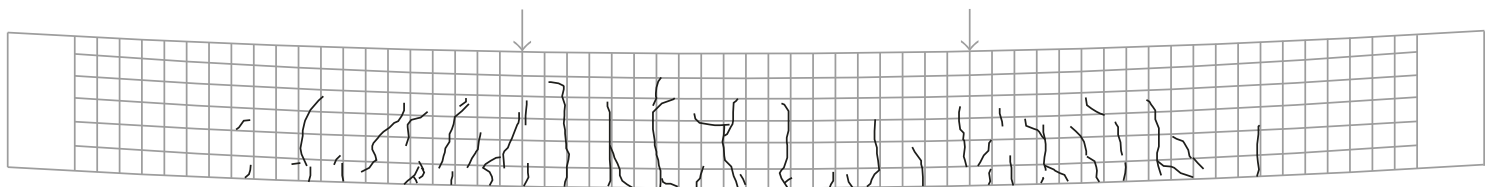

(f)

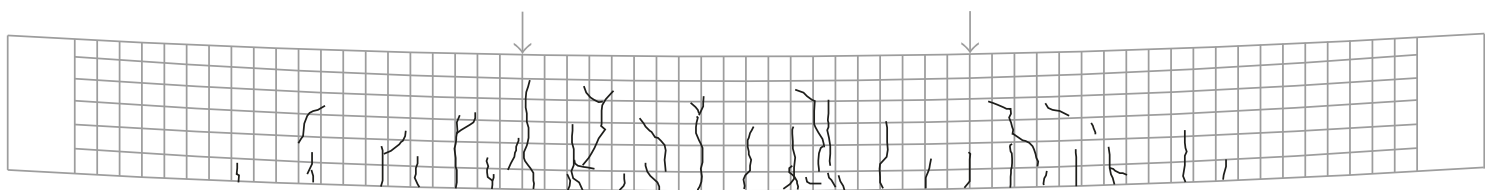

(g)

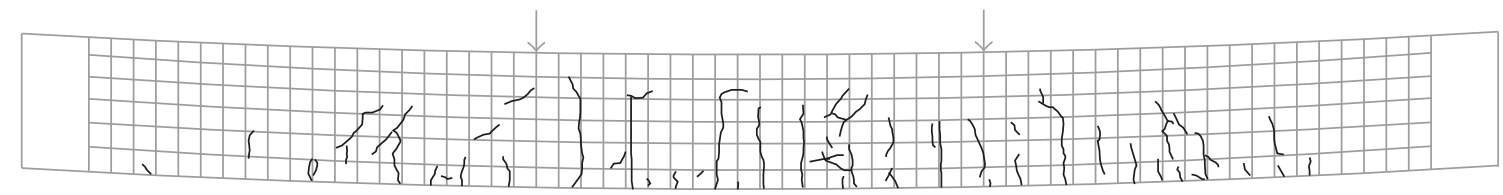

(h)

Figure 8: Crack patterns of beams at failure. (a) RCB-0, (b) RCB-33, (c) RCB-66, (d) RCB-100, (e) HRCB-0, (f) HRCB-33, (g) HRCB-66, and (h) HRCB-100.

the main cracks reduced. In addition, the crack width increased with load increase, and some concrete was damaged because of wide cracks before exerting their energy dissipation capacity.
3.3. Flat Section Assumption. Flat section assumption is the precondition of the bending component's theoretical calculation in Chinese Code for Design of Concrete Structures (GB 50010-2010), which is an important 
assumption in the calculation of concrete theory. Thus, it is essential in the calculation of the bending bearing capacity of corroded reinforced RCA beams. The midspan concrete's average strain distribution along the section height is shown in Figure 9. It can be noted from the figure that the concrete's average strain at each measuring point is proportional to the section height, which accords with the flat section assumption. In addition, the neutral axis changes very little with the RCA replacement ratio, except RCB-0 (this might be because of experiment errors). When the RCA replacement percentage is constant, the neutral axis position moves up slightly with the increase of concrete strength.

3.4. Midspan Load Deflection. The load-deflection curves of each beam, whose support displacements at both ends were modified, are shown in Figure 10. It can be seen that the ultimate load of all beams are relatively close. However, the ultimate deflection varies with the RCA replacement percentage and concrete strength. When the concrete is middle strength, the ultimate deflection of RCB-100 is lower than that of the other beams. When the concrete is high strength, the ultimate deflection decreases with increases in the RCA replacement percentage. This is as a result of concrete brittleness increasing with the increase in the RCA replacement percentage. In particular, the RCA replacement percentage of $100 \%$ has the most effect on the concrete performance, and the concrete antipermeability also declines with the increased RCA replacement percentage.

The load-deflection skeleton curves are shown in Figure 11. Before yielding, the RCA replacement percentage and concrete strength had little influence on the beams, which means the stiffness of corroded reinforced RAC beams changed slightly. This is attributed to steel bar corrosion. After yielding, each beam had close bearing capacity under the same deflection, with the greatest difference being the ultimate midspan deflection value.

3.5. Energy Dissipation Capacity. Unidirectional repetitive loading is similar to low-cycle reverse loading in terms of energy dissipation detection. According to the loaddeflection skeleton curves shown in Figure 11, the enclosed area between the abscissa and the curve presents the beam's energy dissipation capacity, as shown in Table 5.

When the concrete is middle strength, the energy dissipation capacity among RCB-33, RCB-66, and RCB-0 is close, but RCB-100 obviously decreases, with a value of $49 \%$. When the concrete is high strength, HRCB-33 and HRCB-0 have close energy dissipation capacity, and that of HRCB-66 and HRCB-100 decreases with the increase of RCA replacement percentage, with a value of $26 \%$ and $48 \%$, respectively. The value of energy dissipation is associated with ultimate bearing capacity and ultimate deflection. In short, the effects of RCA replacement percentage on energy dissipation capacity vary with concrete strength. However, the energy dissipation capacity decreases significantly with a RCA replacement percentage of $100 \%$, regardless of the concrete strengths.

3.6. Evaluation of Corrosion Degree. The corrosion crack width, position, and length of each specimen were measured before loading, and the actual corrosion ratio and mechanical properties of the corroded longitudinal reinforcement were tested after loading. The results are shown in Table 6.

From the table, we can make the following conclusions. (1) The maximum corrosion crack width increases with increased RCA replacement percentage and declines with increased concrete strength under constant RCA replacement percentage. This is because the porosity and water absorption of the RCAs are larger than those of NCA, which makes chlorine salt easily reach the rebar surface, causing the rebar to corrode faster. Further, the antipermeability of the RCAs decreases with increase in the replacement percentage and causes rebar corrosion in the concrete to form corrosion cracks. (2) The actual corrosion ratio of the longitudinal reinforcement is higher than that of the theoretical corrosion ratio and increases with the RCA replacement percentage as the dense high-strength concrete has greater resistance to chloride penetration. (3) The yield strength of longitudinal reinforcement declines slightly with increase in the RCA replacement percentage. This because RCA and NCA have inherent differences mainly on density and water absorbability, RCA is more vulnerable to chloride ion erosion and its resistance to chloride ion decreases with the increase of RCA replacement percentage [26]. (4) The ultimate strength of the corroded rebar for middle-strength RAC and high-strength RAC declines by $8.88 \%$ and $7.79 \%$ on average compared with the noncorroded rebar, respectively. RCA replacement percentage has negligible effect on the ultimate strength. This may be because the low corrosion ratio of rebar $(5 \%)$ causes less damage to rebar and concrete. (5) The elongation after corrosion declines by $50.81 \%$ on average compared with the noncorroded rebar. This shows that steel bar corrosion has significant influence on the ductility of a steel bar.

The broken beams show that all the concrete touching the corrosion bars were dip-dyed by rust; the corrosion of the bars close to the protective layer was more serious than those far from the protective layer; stirrup corrosion was more serious than corrosion of the longitudinal bars; bottom rebar corrosion was more serious than corrosion of the bars in the middle; the corrosion of the longitudinal bars at the bottom was more serious than the corrosion of the erection bars, as shown in Figure 12.

3.7. Ultimate Bearing Capacity. The ultimate bearing capacity of the test beams serves as the measured values of ultimate bearing capacity $\left(M_{\mathrm{u}}^{\mathrm{t}}\right)$. Because there is no corresponding code for the design of recycled concrete structures in China, amendments of the effect of low 


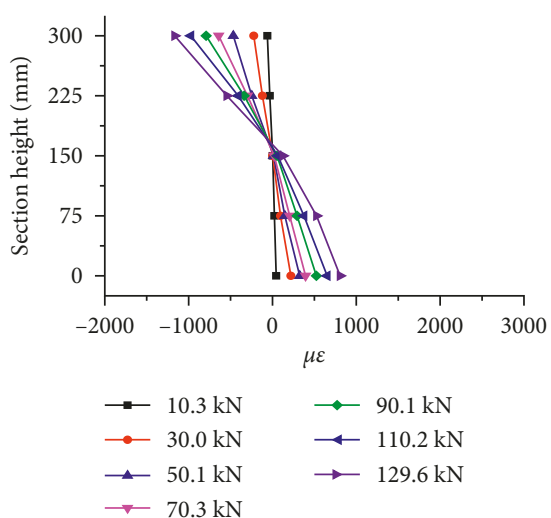

(a)

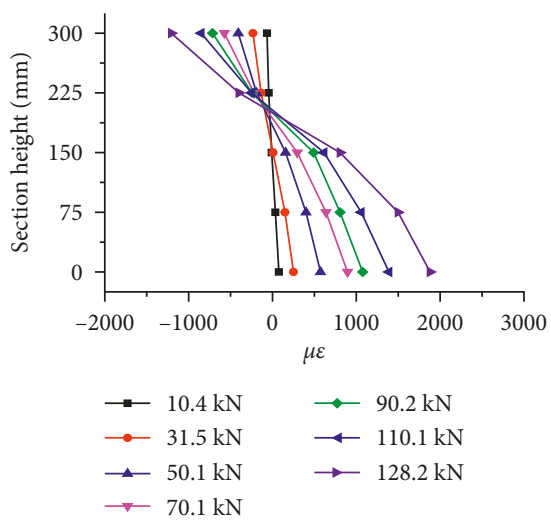

(d)

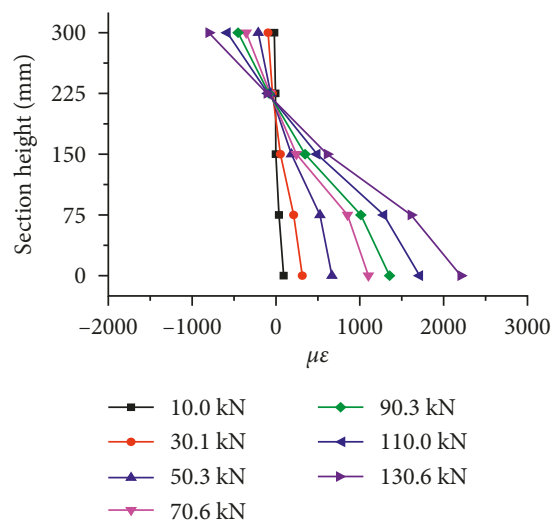

(g)

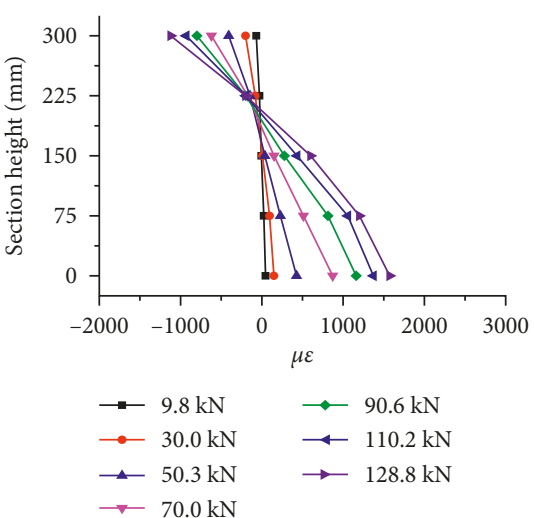

(b)

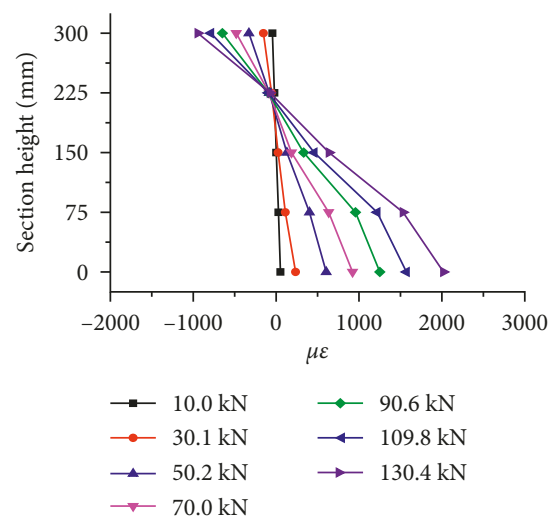

(e)

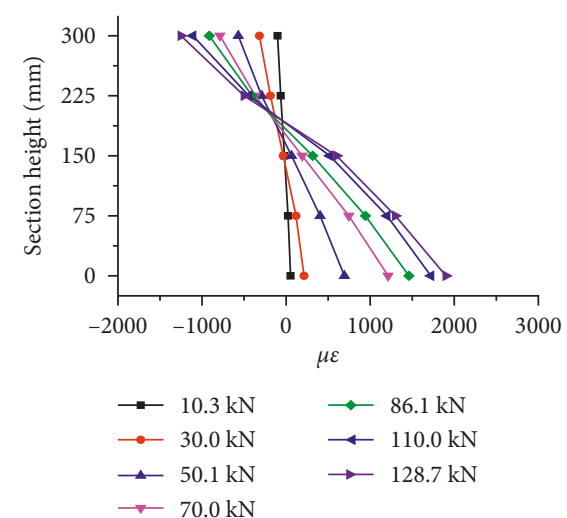

(c)

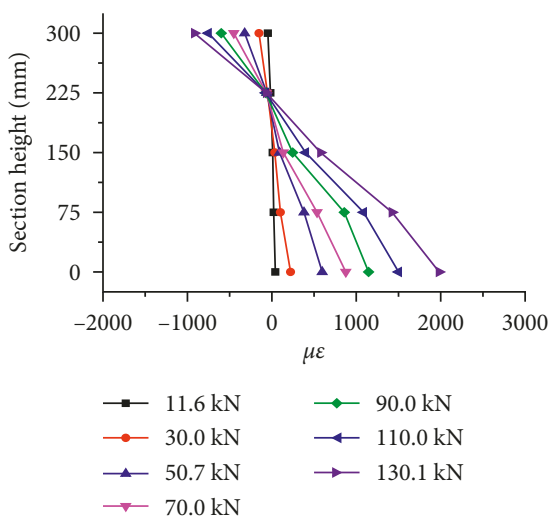

(f)

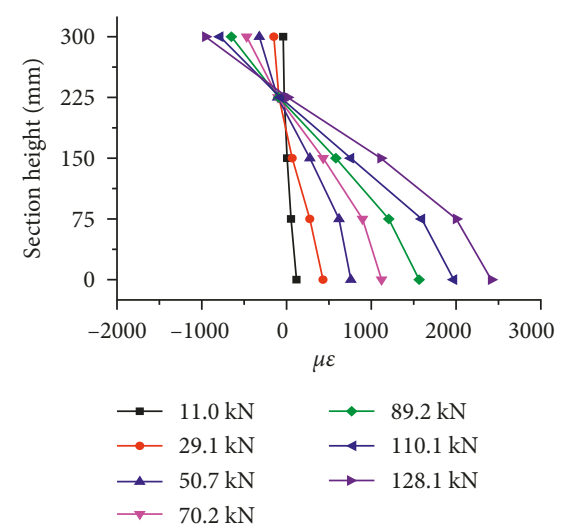

(h)

Figure 9: Concrete strain distribution of the eight specimens. (a) RCB-0, (b) RCB-33, (c) RCB-66, (d) RCB-100, (e) HRCB-0, (f) HRCB-33, (g) HRCB-66, and (h) HRCB-100.

corrosion ratio on the ultimate bearing capacity of reinforced concrete beam were made based on the assumptions and calculation formula of the existing Chinese standard GB 50010-2010.

The effect of the low corrosion ratio on the ultimate bearing capacity of the beam is mainly manifested in the following three aspects: (1) the cross section of the longitudinal bar decreases; (2) the mechanical properties of the longitudinal bar are reduced; and (3) the bonding behavior of the steel bars and concrete is degraded. Therefore, from the above three points on the existing Chinese standard, in the calculation of the formula, the following amendments are needed: (1) according to the actual corrosion ratio of the longitudinal bar, calculate the area of the corroded reinforcement; (2) replace the measured yield strength of the reinforcement with that of the corroded reinforcement; and (3) according to the literature [30], consider the influence of steel bar corrosion ratio on concrete and corroded steel bars coordination work. The calculation formula for the ultimate bearing capacity of corroded reinforced RAC beams is as follows: 


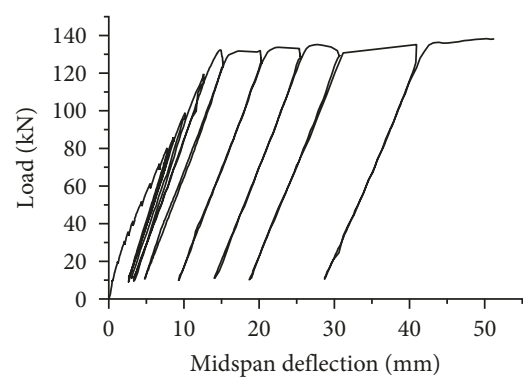

(a)

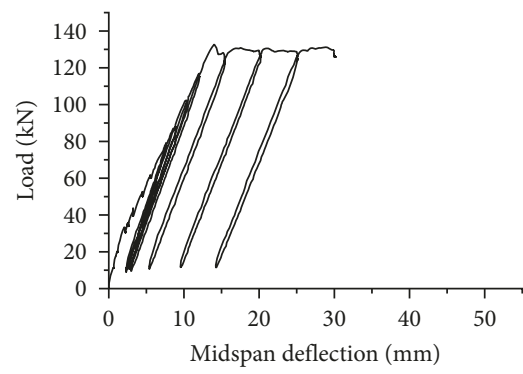

(d)

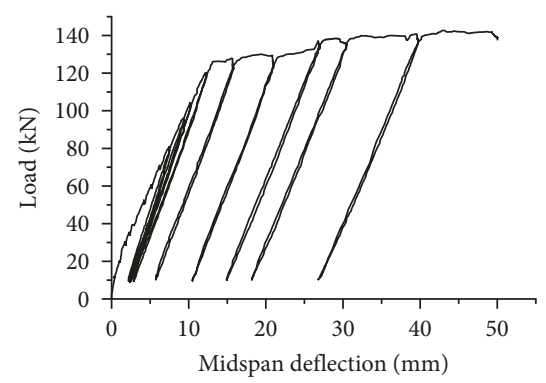

(b)

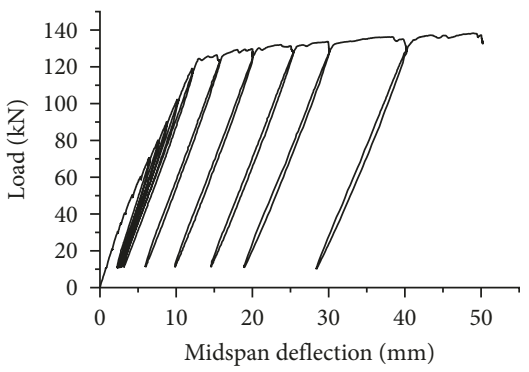

(e)

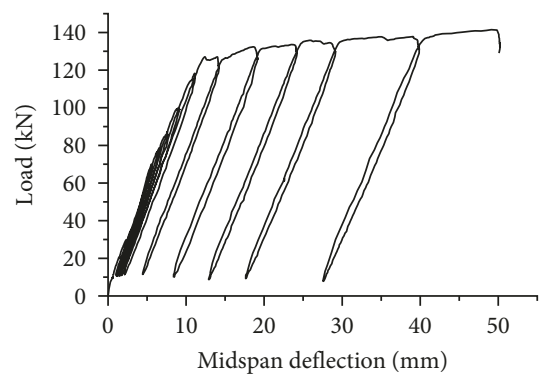

(c)

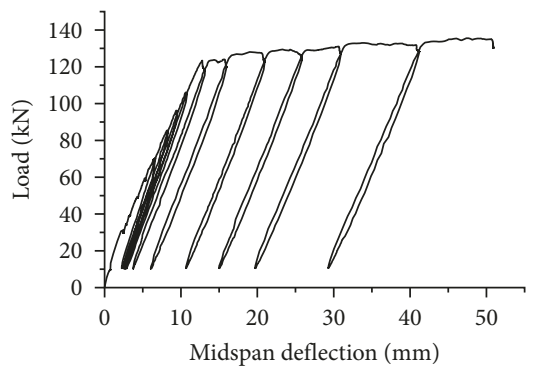

(f)

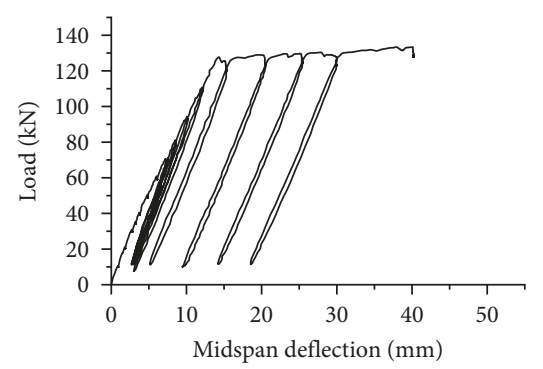

(g)

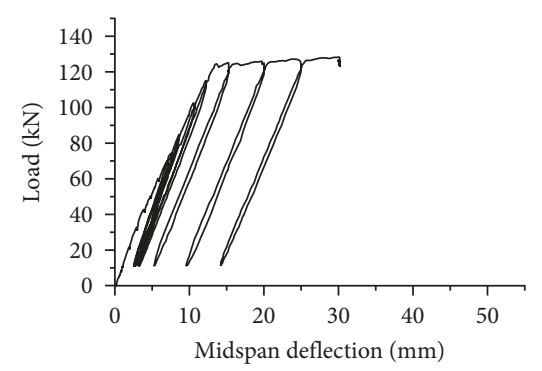

(h)

Figure 10: Load-deflection curves of the eight specimens. (a) RCB-0, (b) RCB-33, (c) RCB-66, (d) RCB-100, (e) HRCB-0, (f) HRCB-33, (g) HRCB-66, and (h) HRCB-100.

$$
\begin{aligned}
\alpha_{1} f_{\mathrm{c}} b x & =f_{\mathrm{y}}^{\prime} A_{\mathrm{s}}^{\prime}, \\
M_{\mathrm{u}}^{\mathrm{c} 1} & =\alpha_{1} f_{\mathrm{c}} b x\left(h_{0}-\frac{x}{2}\right), \\
M_{\mathrm{u}}^{\mathrm{c} 2} & =\eta M_{\mathrm{u}}^{\mathrm{c} 1}, \\
A_{\mathrm{s}}^{\prime} & =A_{\mathrm{s}}\left(1-L_{\mathrm{am}}\right), \\
\eta & = \begin{cases}1 & L_{\mathrm{am}}<1.2 \\
1.0168-0.014 L_{\mathrm{am}} & 1.2 \leq L_{\mathrm{am}} \leq 6.0,\end{cases}
\end{aligned}
$$

where $\alpha_{1}$ denotes the high-strength concrete reduction factor calculated using the Chinese standard GB50010-2010; $f_{\mathrm{c}}$ denotes the measured axial compressive strength of concrete; $b$ denotes the beam section width; $x$ denotes the height of the equivalent compression zone of the beam section; $f_{\mathrm{y}}^{\prime}$ denotes the measured yield strength of the corroded reinforcement bar; $A_{\mathrm{s}}^{\prime}$ denotes the longitudinal reinforcement area considering the actual corrosion ratio; $A_{s}$ denotes the noncorrosive longitudinal reinforcement area; $L_{\mathrm{am}}$ denotes the actual corrosion ratio of the longitudinal reinforcement; $h_{0}$ denotes the effective height of the beam section; $M_{\mathrm{u}}^{\mathrm{cl}}$ denotes the computed bending moment considering the cross section decrease of longitudinal bar and the yield strength change; $M_{\mathrm{u}}^{\mathrm{c} 2}$ denotes the computed bending moment considering the influence of steel bar corrosion ratio on concrete and corroded steel bar coordination work; and $\eta$ denotes the coordination coefficient of steel bar and concrete considering the actual corrosion ratio.

The characteristic value of the ultimate bearing capacity of each beam is shown in Table 7. $M_{\mathrm{u}}^{\mathrm{t}} / M_{\mathrm{u}}^{\mathrm{c} 2}$ denotes the ratio of the measured ultimate bearing capacity to the computed ultimate bearing capacity considering the influence of steel bar corrosion ratio.

From Table 7, it can be seen that most of the measured values are larger than the computed values, except for HRCB-100. Thus, HRCB-100 has no safety reserve. Owing to the fact that concrete contains RCA in this research, the influence of the RCA replacement percentage on the ultimate bearing capacity is considered on the basis of $M_{\mathrm{u}}^{\mathrm{c} 2}$. According to the literature [31], the correction coefficient $\beta$ 


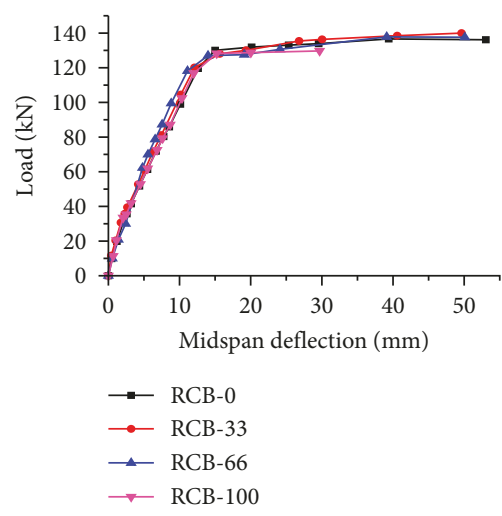

(a)

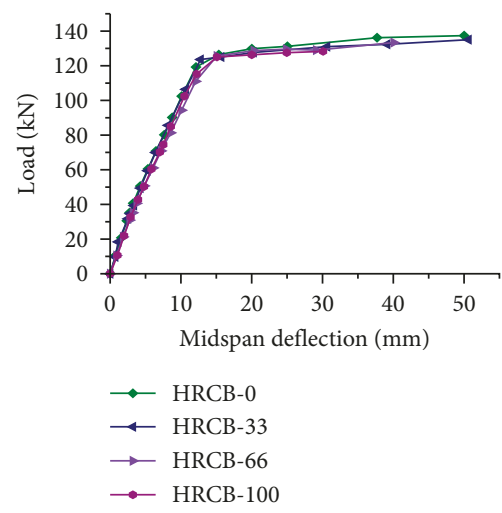

(b)

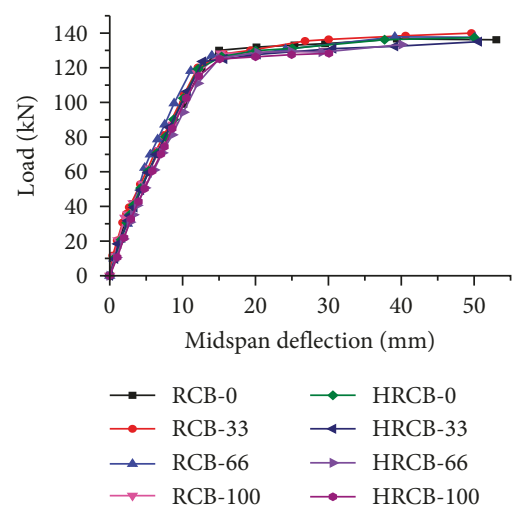

(c)

FIGURE 11: Skeleton curves of load deflection: (a) middle-strength concrete specimens, (b) high-strength concrete specimens, and (c) all specimens.

TABLE 5: Experimental results of energy dissipation.

\begin{tabular}{lcc}
\hline Specimen & Energy dissipation $(\mathrm{kN} \cdot \mathrm{mm})$ & Relative energy dissipation \\
\hline RCB-0 & 6008.03 & 1.00 \\
RCB-33 & 5877.43 & 0.98 \\
RCB-66 & 6044.27 & 1.01 \\
RCB-100 & 3090.23 & 0.51 \\
HRCB-0 & 5813.11 & 1.00 \\
HRCB-33 & 5799.32 & 0.99 \\
HRCB-66 & 4309.04 & 0.74 \\
HRCB-100 & 2995.92 & 0.52 \\
\hline
\end{tabular}

TABLE 6: Corrosion ratios and mechanical properties of tensile corroded steel bar.

\begin{tabular}{lcccccc}
\hline Specimen & $\begin{array}{c}\text { Maximum crack } \\
\text { width }(\mathrm{mm})\end{array}$ & $\begin{array}{c}\text { Actual corrosion } \\
\text { ratio (\%) }\end{array}$ & $\begin{array}{c}\text { Theoretical corrosion } \\
\text { ratio (\%) }\end{array}$ & $f_{\mathrm{y}}^{\prime}(\mathrm{MPa})$ & $f_{\mathrm{u}}^{\prime}(\mathrm{MPa})$ & Elongation $(\%)$ \\
\hline RCB-0 & 1.00 & 5.23 & 5.00 & 493 & 598 & 10.41 \\
RCB-33 & 1.12 & 5.26 & 5.00 & 488 & 590 & 10.12 \\
RCB-66 & 1.36 & 5.33 & 5.00 & 463 & 579 & 7.63 \\
RCB-100 & 1.56 & 5.45 & 5.00 & 452 & 584 & 9.44 \\
HRCB-0 & 0.94 & 5.15 & 5.00 & 489 & 594 & 10.97 \\
HRCB-33 & 1.08 & 5.27 & 5.00 & 495 & 595 & 11.05 \\
HRCB-66 & 1.28 & 5.36 & 5.00 & 475 & 600 & 590 \\
HRCB-100 & 1.52 & 5.40 & 5.00 & 51.10 & 11.13 \\
\hline
\end{tabular}

$f_{\mathrm{y}}^{\prime}$ denotes the yield strength of corroded tensile reinforcement; $f_{\mathrm{u}}^{\prime}$ denotes the ultimate strength of corroded tensile reinforcement.

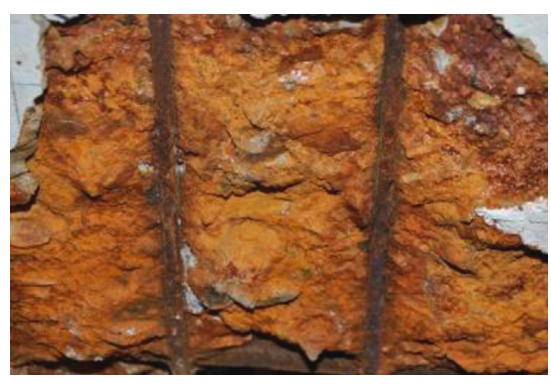

(a)

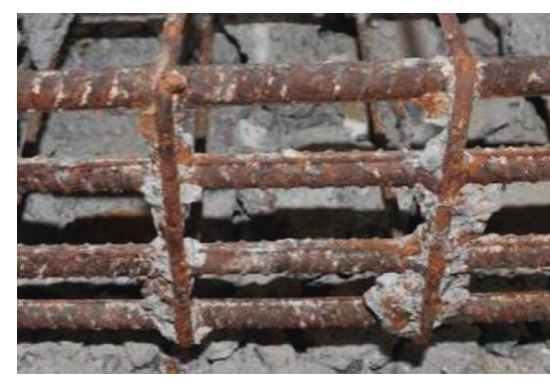

(b)

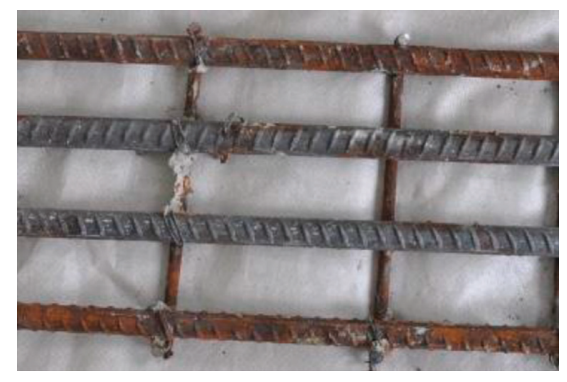

(c)

FIgURE 12: (a) The concrete touching the corrosion bars were dip-dyed by rust. (b, c) The corroded steel bars. 
TABLE 7: Characteristic values of bearing capacity.

\begin{tabular}{|c|c|c|c|c|c|}
\hline Specimen & $M_{\mathrm{u}}^{\mathrm{t}}(\mathrm{MPa})$ & $M_{\mathrm{u}}^{\mathrm{c} 2}(\mathrm{MPa})$ & $M_{\mathrm{u}}^{\mathrm{t}} / M_{\mathrm{u}}^{\mathrm{c} 2}$ & $M_{\mathrm{u}}^{\mathrm{c} 4}(\mathrm{MPa})$ & $M_{\mathrm{u}}^{\mathrm{t}} / M_{\mathrm{u}}^{\mathrm{c} 4}$ \\
\hline RCB-0 & 69.1 & 64.6 & 1.07 & 64.6 & 1.07 \\
\hline RCB-33 & 70.1 & 64.1 & 1.09 & 59.8 & 1.17 \\
\hline RCB-66 & 69.1 & 61.2 & 1.13 & 53.1 & 1.30 \\
\hline RCB-100 & 65.7 & 59.6 & 1.10 & 47.7 & 1.37 \\
\hline HRCB-0 & 68.7 & 67.4 & 1.02 & 67.4 & 1.02 \\
\hline HRCB-33 & 67.6 & 67.5 & 1.00 & 63.1 & 1.07 \\
\hline HRCB-66 & 66.7 & 66.0 & 1.01 & 57.3 & 1.16 \\
\hline HRCB-100 & 64.2 & 64.7 & 0.99 & 51.8 & 1.24 \\
\hline
\end{tabular}

is multiplied, and its value is defined as follows: no RCA, that is, RCA replacement percentage is $0, \beta=1$; full RCA, that is, RCA replacement percentage is $100 \%, \beta=0.8$. When the replacement percentage is between 0 and $100 \%$, it is determined by linear interpolation. The calculation formula is as follows:

$$
\begin{aligned}
\alpha_{1} f_{\mathrm{c}} \beta b x & =f_{\mathrm{y}}^{\prime} A_{\mathrm{s}}^{\prime}, \\
M_{\mathrm{u}}^{\mathrm{c} 3} & =\alpha_{1} f_{\mathrm{c}} \beta b x\left(h_{0}-\frac{x}{2}\right), \\
M_{\mathrm{u}}^{\mathrm{c} 4} & =\eta M_{\mathrm{u}}^{\mathrm{c} 3},
\end{aligned}
$$

where $M_{\mathrm{u}}^{\mathrm{c} 4}$ denotes the computed bending moment considering the influence of steel bar corrosion ratio and RCA replacement percentage, $M_{\mathrm{u}}^{\mathrm{t}} / M_{\mathrm{u}}^{\mathrm{c}}$ denotes the ratio of the measured ultimate bearing capacity to the computed ultimate bearing capacity considering the influence of steel bar corrosion ratio and RCA replacement percentage, and the other parameters are the same as in (2).

It can be seen that the values of $M_{\mathrm{u}}^{\mathrm{t}} / M_{\mathrm{u}}^{\mathrm{c} 4}$ are larger than 1.00 , the mean value is 1.175 , the standard deviation is 0.114 , the coefficient of variation is 0.097 , and the discretization is small. The above values indicate that the computed ultimate bearing capacity $\left(M_{\mathrm{u}}^{\mathrm{c} 4}\right)$ of the corroded reinforced RAC beam is less than the measured value $\left(M_{\mathrm{u}}^{\mathrm{t}}\right)$ and all beams have a safety reserve, which shows that this amendment method considering the influence of steel bar corrosion ratio and RCA replacement percentage on the ultimate bearing capacity of the corroded reinforced RAC beam is feasible.

\section{Conclusions}

Based on tests performed on material properties and on comparisons made in terms of flexural behavior of corroded reinforced RAC beams, the following conclusions have been drawn:

(1) During the corroded reinforced RAC beam crosssectional loading process, they undergo four stages, elasticity, cracking, yield, and failure, regardless of RCA replacement percentage and concrete strengths.

(2) The concrete's strain is in good agreement with the flat section assumption, and the influence of RCA replacement percentage and concrete strengths on it is negligible.

(3) The ultimate bearing capacity of middle-strength RAC and high-strength RAC declines by $1.18 \%$ and $3.74 \%$ on average compared with reference concrete, respectively. This shows that RCA replacement percentage and concrete strengths have little influence on ultimate bearing capacity. The computed value considering the influence of steel bar corrosion ratio and RCA replacement percentage on the ultimate bearing capacity of the corroded reinforced RAC beam is in good agreement with the measured value.

(4) The value of displacement ductility ratio for middlestrength RAC and high-strength RAC declines by $7.87 \%$ and $24.22 \%$ on average compared with reference concrete, respectively. This shows that RCA replacement percentage has little influence on the properties of medium-strength concrete but affects the properties of high-strength concrete significantly.

(5) According to the results of ductility and energy dissipation capacity, we can conclude that RCA replacement percentage of $100 \%$ should not be adopted in chlorine salt and other corrosive environments; the RCA replacement percentage of highstrength concrete should be lower than $30 \%$ and that of low and medium-strength concrete should be no more than $60 \%$.

\section{Conflicts of Interest}

The authors declare that there are no conflicts of interest regarding the publication of this paper.

\section{Acknowledgments}

The authors would like to appreciate the funding from National Natural Science Foundation of China (no. 51438007).

\section{References}

[1] T. C. Hansen, "Recycled aggregate and recycled aggregate concrete, second state of art report, development from 19451985," Materials and Structures, vol. 19, no. 5, pp. 201-246, 1986.

[2] J. Shang, Z. Li, and X. Yang, "Experimental study on characteristics of recycled coarse aggregate," Architecture Technology, vol. 34, no. 1, pp. 52-53, 2003.

[3] W. Wang and L. Liu, "Research of recycled concrete aggregate," Concrete and Cement Products, vol. 4, pp. 9-12, 2001. 
[4] J. Li, J. Xiao, and Z. Sun, "Properties of recycled coarse aggregate and its influence on recycled concrete," Journal of Building Materials, vol. 7, no. 4, pp. 390-395, 2004.

[5] V. Corinaldesi, "Mechanical and elastic behaviour of concretes made of recycled-concrete coarse aggregates," Construction and Building Materials, vol. 24, no. 9, pp. 1616-1620, 2010.

[6] M. Chakradhara Rao, S. K. Bhattacharyya, and S. V. Barai, "Influence of field recycled coarse aggregate on properties of concrete," Materials and Structures, vol. 44, no. 1, pp. 205220, 2011.

[7] K. H. Yang, H. S. Chung, and A. Ashour, "Influence of type and replacement level of recycled aggregates on concrete properties," ACI Materials Journal, vol. 105, no. 3, pp. 289296, 2008.

[8] R. K. Dhir and M. C. Limbachiya, "Suitability of recycled aggregate for use in BS 5328 designated mixes," Proceedings of the Institution of Civil Engineers-Structures and Buildings, vol. 134, no. 3, pp. 257-274, 1999.

[9] S. M. Gupta, "Strength characteristics of concrete made with demolition waste as coarse aggregate," in Proceedings of the International Conference on Recent Development in Structural Engineering, pp. 364-373, 2001.

[10] S. W. Tabsh and A. S. Abdelfatah, "Influence of recycled concrete aggregates on strength properties of concrete," Construction and Building Materials, vol. 23, no. 2, pp. 11631167, 2009.

[11] W. Cao, K. Zhu, W. Jiang, G. Chen, D. Lin, and S. Peng, "Experimental study on stress-strain constitutive relationship of high strength recycled concrete," Journal of Natural Disasters, vol. 25, no. 2, pp. 167-172, 2016.

[12] L. Zhang and Y. Xu, "Compressive strength and elastic modulus of recycled aggregate concrete," Low Temperature Architecture Technology, no. 1, pp. 6-8, 2008.

[13] J. Xiao and H. Falkner, "Bond behaviour between recycled aggregate concrete and steel rebars," Construction and Building Materials, vol. 21, no. 2, pp. 395-401, 2007.

[14] K. Ishill, "Flexible characteristic of RC beam with recycled coarse aggregate," in Proceeding of the 25th JSCE Annual Meeting, pp. 886-887, Kanto Branch, Japan, 1998.

[15] G. Fathifazl, A. G. Razaqpur, O. Burkan Isgor, A. Abbas, B. Fournier, and S. Foo, "Flexural performance of steelreinforced recycled concrete beams," ACI Structural Journal, vol. 106, no. 6, pp. 858-867, 2009.

[16] I. S. Ignjatović, S. B. Marinković, Z. M. Mišković, and A. R. Savic, "Flexural behavior of reinforced recycled aggregate concrete beams under short-term loading," Materials and Structures, vol. 46, no. 6, pp. 1045-1059, 2013.

[17] W. C. Choi, H. D. Yun, and S. W. Kim, "Flexural performance of reinforced recycled aggregate concrete beams," Magazine of Concrete Research, vol. 64, no. 9, pp. 837-848, 2012.

[18] S. H. Kim, B. S. Han, J. M. Ahn, and S. W. Shin, "Flexural behaviors of reinforced concrete beams containing recycled coarse aggregate," Proceedings of Architecture Institute of Korea, vol. 22, no. 1, pp. 83-86, 2002.

[19] I. Maruyama, M. Sogo, T. Sogabe, R. Sato, and K. Kawai, "Flexural properties of reinforced recycled concrete beams," in Proceedings of the International RILEM Conference on the Use of Recycled Materials in Buildings and Structures, pp. 525-535, Barcelona, Spain, 2004.

[20] L. Evangelista and J. de Brito, "Flexural behavior of reinforced concrete beams made with fine recycled concrete aggregate," KSCE Journal of Civil Engineering, vol. 21, no. 1, pp. 353-363, 2017.
[21] G. Fathifazl, A. G. Razaqpur, O. B. Isgor, A. Abbas, B. Fournier, and S. Foo, "Shear capacity evaluation of steel reinforced recycled concrete (RRC) beams," Engineering Structures, vol. 33, no. 3, pp. 1025-1033, 2011.

[22] M. Etxeberria, A. R. Marí, and E. Vázquez, "Recycled aggregate concrete as structural material," Materials and Structures, vol. 40, no. 5, pp. 529-541, 2007.

[23] F. Cao, C. Wang, L. Liu, Y. Xin, J. Li, and Z. Tian, "Experimental study and rigidity analysis on corroded reinforced recycled concrete beams," Building Structures, vol. 45, no. 10, pp. 49-55, 2015.

[24] H. Yang, Z. Deng, Y. Qin, and L. Lv, "A study on the bond behavior of corroded reinforced concrete containing recycled aggregates," Advances in Materials Science and Engineering, vol. 2015, Article ID 249301, 9 pages, 2015.

[25] Z. Roumiana, B. B François, S. Frédéric, and W. Eric, “Assessment of the surface permeation properties of recycled aggregate concrete," Cement and Concrete Composites, vol. 25, no. 2, pp. 223-232, 2003.

[26] K. Xiao, Z. Lin, H. Wan et al., "Study on chloride ion permeability of recycled concrete," Shandong Building Materials, vol. 25, no. 1, pp. 31-33, 2004.

[27] China Standards Publication, Pebble and Crushed stone for Construction, GB/T 14685-2011, Standard Press of China, Beijing, China, 2011.

[28] China Standards Publication, Recycled Coarse Aggregate for Concrete, GB/T 25177-2010, Standard Press of China, Beijing, China, 2011.

[29] Durability Theory and Design Methods of Concrete Structure in the Chloric Environment, Science Press, Beijing, China, 2011.

[30] W. L. Jin and Y. X. Zhao, "Test study on bending strength of corroded reinforced concrete beams," Industrial Construction, vol. 31, no. 5, pp. 9-11, 2001.

[31] G. Bai, Y. Chang, and Y. Li, Study on Reduction Factor of Equivalent Compressive Strength and Numerical Simulation of Compression Test of Recycled Concrete, Xi'an University of Architecture and Technology, Xi'an, China, 2011. 


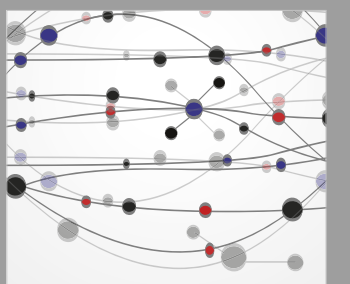

The Scientific World Journal
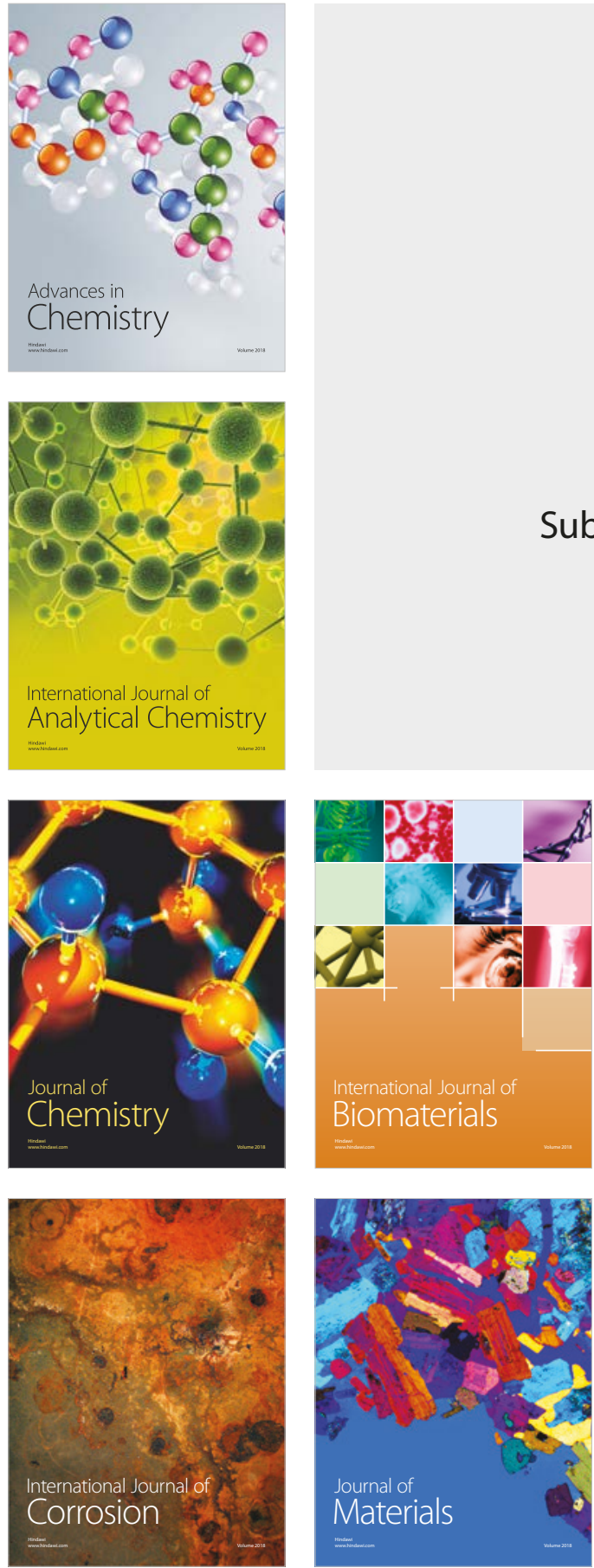

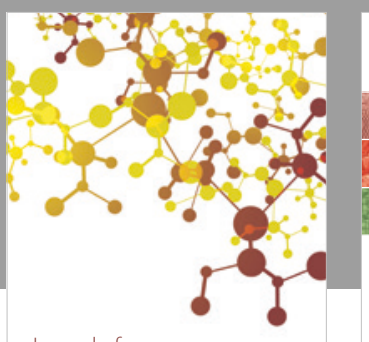

Journal of

Applied Chemistry
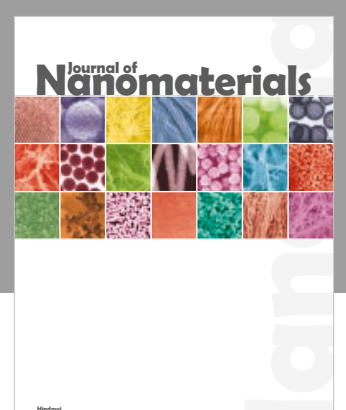

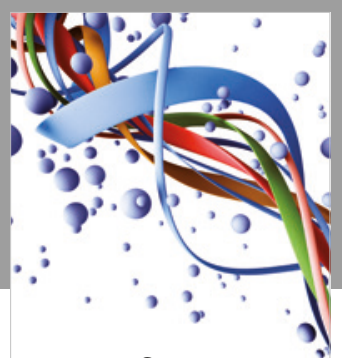

Scientifica

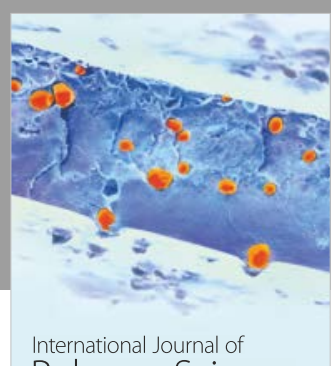

Polymer Science

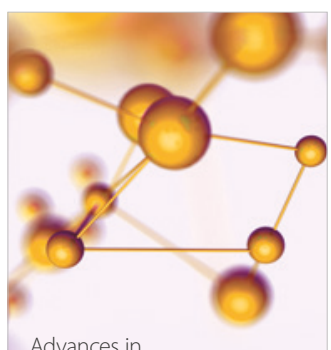

Physical Chemistry
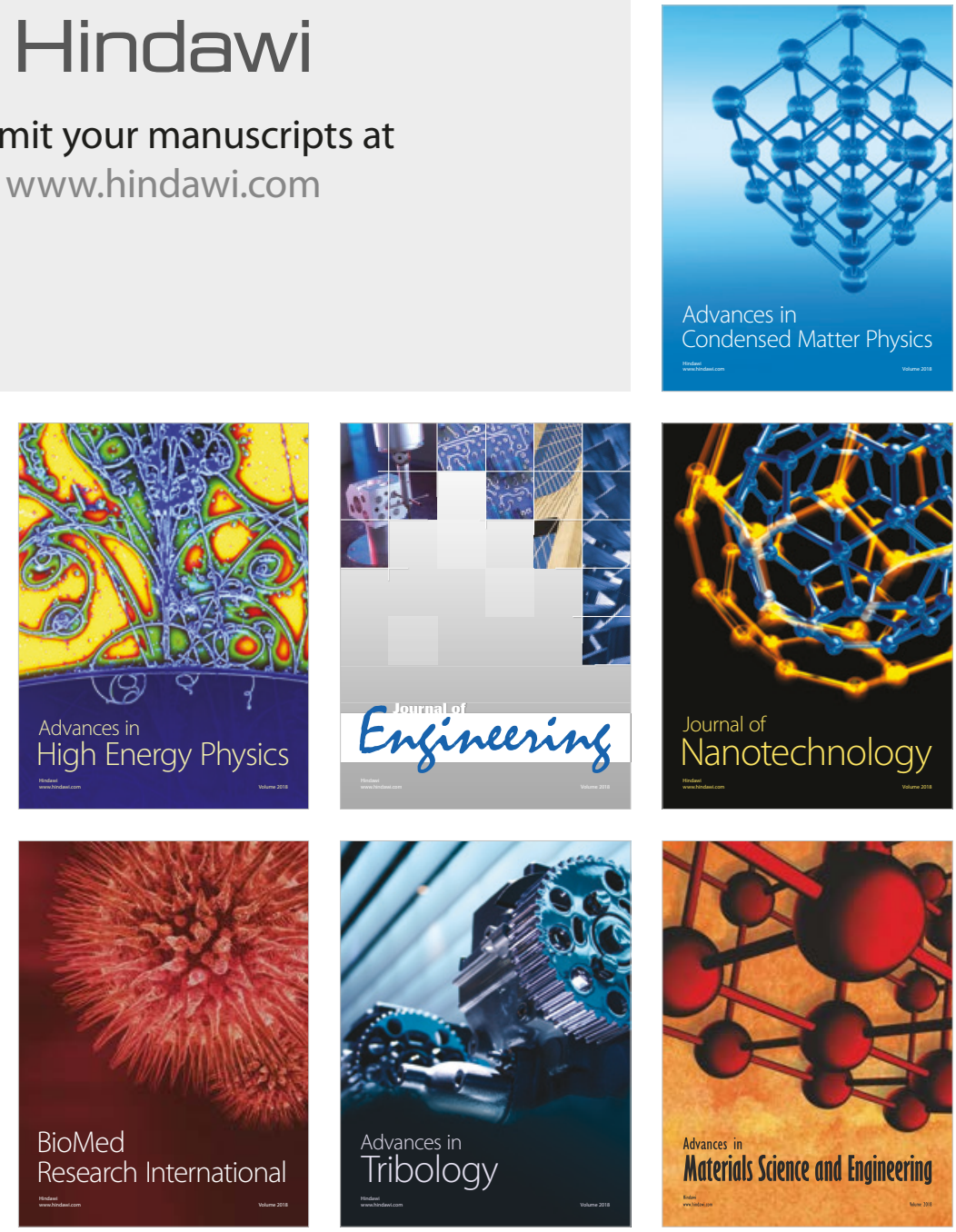